\title{
Medicare Balance Billing Restrictions: Impacts on Physicians and Beneficiaries
}

\author{
Robin McKnight* \\ University of Oregon and NBER \\ September 2004
}

\begin{abstract}
:
Recent publicity about "concierge physicians" has raised concerns about the potential adverse effects of allowing physicians to bill their patients for fees that are above normal copayments and insurance reimbursements. In particular, consumers who are unable to afford the additional costs of such physicians are concerned that their access to highquality medical care could be compromised. Such concerns in the context of Medicare led states and the federal government, beginning in the late 1980s, to restrict the ability of physicians to "balance bill" beneficiaries for charges in excess of the copayment and reimbursement amounts approved by Medicare. In this paper, I provide empirical evidence that this policy change resulted in an $8 \%$ reduction in out-of-pocket medical expenditures by elderly households. In spite of the change in marginal reimbursement to physicians, however, I find little evidence that the restrictions affected quantity or quality of care.
\end{abstract}

JEL Classification number: I1

Keywords: price controls, Medicare, physician reimbursement

\footnotetext{
*I am grateful to Trudy Cameron, Mark Duggan, Amy Finkelstein, Jon Gruber, Walter Nicholson, Jim Poterba, Jonathan Reuter, Wes Wilson, and workshop participants at Amherst College for helpful comments and discussions. Funding from the National Institute on Aging, through Grant \#K12-AG00983 to the National Bureau of Economic Research, is gratefully acknowledged.
} 


\section{Introduction}

Recent publicity about "concierge physicians," who require substantial out-of-pocket payments in excess of regular reimbursement by health insurance companies, has raised concerns about the potential adverse effects of allowing physicians to bill some of their patients for fees that are above normal reimbursement. These physicians charge annual fees in exchange for special services, such as cell-phone access to doctors, same-day appointments, and accompaniment to specialist visits. Consumers who are unable to afford the additional costs of such physicians are concerned that their access to high-quality health care could be compromised. A 2002 New York Times editorial, for example, worried that, "if a new category of 'insurance-plus' takes root, it will exacerbate what some patients and doctors already believe is a two-tier medical system."

This very concern led to one of the most important changes in the structure of the Medicare physician program since its inception. Before the late 1980s, physicians participating in Medicare could "balance bill" beneficiaries for the difference between the physician charge and Medicare's reimbursement level. In 1984, liability for balance billing was $\$ 77$ per beneficiary, or about $27 \%$ of the total part B out-of-pocket liability faced by beneficiaries (Health Care Financing Review, 2000). During the late 1980s and early 1990s, in an effort to protect beneficiaries from out-of-pocket liabilities, state and federal policies restricted the ability of physicians to balance bill Medicare beneficiaries. These restrictions, like the more recent controversy about concierge physicians, raised concerns about how balance billing — or the lack thereof — affects access to care and the quality of care provided.

Economic theory suggests that physicians could have responded to restrictions on balance billing by adjusting the quantity and/or quality of services they provided to Medicare 
beneficiaries. Theory does not, however, provide unambiguous predictions about the direction of the effect on physician behavior. The predictions of standard models vary, depending on whether the model incorporates quality of care as a choice variable or allows for features such as demand inducement, physician income targeting, or demand constraints. Furthermore, empirical research on the effects of balance billing restrictions has been quite limited. The U.S. General Accounting Office (GAO) analyzed data from the first four states that implemented policies, but concluded that the available data covered "too short of a time to determine whether physicians modified their behavior in response to the laws" (GAO, 1989, p. 37). In this paper, I provide new empirical evidence on physician responses to Medicare balance billing restrictions, using variation in the timing and location of restrictions to identify their effects.

I begin by quantifying the effects of balance billing restrictions on household out-ofpocket medical expenditures, using data from the Consumer Expenditure Survey (CEX). My analysis indicates that balance billing restrictions led to an annual decline of approximately $\$ 120$ in out-of-pocket expenditures for physician services among households with elderly members. ${ }^{1}$ This decline represents an $8 \%$ reduction in overall spending for medical services among elderly households.

Next, I consider the effects of balance billing restrictions on the quantity of care received by Medicare beneficiaries. Because balance billing restrictions decreased the marginal reimbursement for providing an additional medical service to the subset of Medicare beneficiaries who were previously paying balance bills, physicians may have responded by changing the supply of care available to Medicare patients. Using data from the

\footnotetext{
${ }^{1}$ Dollar amounts are in real 1999 dollars.
} 
National Health Interview Survey (NHIS), I find no evidence that the number of doctor visits provided to Medicare beneficiaries changed.

Since some specialties historically balance-billed Medicare beneficiaries more than others and therefore faced larger changes in marginal reimbursement than other specialties, I also consider the impact separately by physician specialty. For example, balance bills added an average of $7.5 \%$ to the Medicare allowed charges for the services of a family practitioner, $23 \%$ for the services of an anesthesiologist, and $24 \%$ for the services of an oral surgeon in 1990 (Helbing and Petrie, 1992). Even among specialties that had relatively high balance billing rates, however, I find little evidence of a change in the quantity of care.

To assess the effects of balance billing restrictions on the duration of doctor visits and on the type of follow-up plans, I turn to a survey of doctor visits, the National Ambulatory Medical Care Survey (NAMCS). I interpret measures such as duration of doctor visits as proxies for the quality of care. Balance billing restrictions have no significant impact on the duration of doctor visits, but do have a significant, negative impact on the likelihood of planning a follow-up telephone call. This result may reflect a decision by physicians to spend less time with their Medicare patients in response to balance billing restrictions.

Finally, I consider the general equilibrium effects of the restrictions in the market for physicians. Using aggregate data on the number of physicians per capita of each specialty across states and over time, I find no significant evidence that the supply of physicians declined in response to the decreased reimbursement.

In summary, the empirical results suggest that balance billing restrictions had few, if any, consequences for the quality or quantity of care to Medicare beneficiaries. The primary impact, then, was a decrease in out-of-pocket expenditures among the subset of beneficiaries 
who were previously paying balance bills, which was the intention of the legislation.

Nevertheless, this impact represents redistribution from physicians to Medicare beneficiaries.

The welfare implications of the policy change, then, depend on the relative incomes and importance assigned to affected physicians and affected Medicare beneficiaries in the social welfare function.

\section{Background and Legislative History}

Medicare historically reimbursed physicians for their "customary, prevailing and reasonable" fee, which meant that physicians were reimbursed by Medicare for the lower of “(1) the actual charge (the billed amount), (2) the physician's customary charge (the median charge of all charges by that physician for that service over the previous 12 months), or (3) the prevailing charge (sufficient to cover the customary charge for three out of four bills for all physicians in the geographic area)" (GAO, 1989, p. 9). Before 1984, doctors had a choice of "accepting assignment" or not. Doctors who accepted assignment would receive $80 \%$ of the Medicare allowed charge directly from Medicare and could bill the patient for the $20 \%$ copayment, but were not permitted to balance bill. Doctors who did not accept assignment would bill the patient for the full cost of the service, including the balance bill, and the patient would be reimbursed by Medicare for $80 \%$ of Medicare's allowed charge. ${ }^{2}$ Hence, physicians who did not accept assignment were permitted to balance bill, but ran the risk of receiving no payment for any of their charges. In contrast, physicians who did accept assignment were guaranteed payment of at least $80 \%$ of the Medicare fee, but were not permitted to balance bill.

\footnotetext{
${ }^{2}$ Medigap policies typically have not covered balance bills, so balance bills represent additional out-ofpocket costs to beneficiaries (GAO, 1989; Rice, 1984).
} 
In the 1980 s, there was growing concern about the financial liability faced by Medicare beneficiaries and, as a result, a number of measures were taken to encourage physicians to accept assignment. In 1984, the "Participating Physician and Supplier Program" was introduced, which defined a "participating physician" as a doctor who agreed to always accept assignment for Medicare patients. Between 1984 and 1990, numerous efforts were made to persuade doctors to "participate." Efforts included publishing a directory of participating doctors for Medicare beneficiaries and offering a 5\% higher Medicare allowed charge to participating doctors than to non-participating doctors. Also, the Omnibus Budget Reconciliation Act of 1986 (OBRA 86) restricted the growth of billed charges for nonparticipating doctors whose charges were greater than $115 \%$ of the national average prevailing charge for the procedure to a nominal growth rate of $1 \%$ per year.

Effective in February 1986, doctors in Massachusetts were required to accept assignment or lose their license to practice in the state. This law (and subsequent laws that restricted balance billing in other states) did not require doctors to treat Medicare beneficiaries; it only required that, if they chose to treat Medicare beneficiaries, they could not balance bill them. To illustrate the impact of this legal change, consider a physician in Massachusetts in 1985 , who charged $\$ 120$ per office visit and did not accept assignment. If Medicare's allowed charge was $\$ 100$, the physician would receive $\$ 80$ from Medicare, a $\$ 20$ copayment from the beneficiary, plus an additional $\$ 20$ balance bill from the beneficiary. After the passage of this law, the doctor could not charge the beneficiary for the $\$ 20$ balance bill. Thus, the physician's total reimbursement for this visit fell by $17 \%$ as a result of the policy change and the patient's out-of-pockets costs for the visit fell by $50 \%$. 
In 1987, Connecticut, Vermont and Rhode Island implemented mandatory assignment laws that applied to relatively low-income beneficiaries. Based on their income, $68 \%$ of Connecticut beneficiaries, $49 \%$ of Rhode Island beneficiaries, and $90 \%$ of Vermont beneficiaries were eligible for mandatory assignment (GAO, 1989). Effective January 1, 1990, Rhode Island's mandatory assignment law was expanded to cover all beneficiaries. Pennsylvania required all doctors to accept assignment, effective September 8, 1990.

The Omnibus Budget Reconciliation Act of 1989 (OBRA 89) imposed federal restrictions on balance billing (beginning in 1991) and legislated a new Medicare fee schedule (beginning in 1992). For each procedure/region, there was a "recognized payment amount" for non-participating physicians, which was $95 \%$ of the recognized payment amount for participating physicians. There was also a "limiting charge" which was the upper bound on billed charges by non-participating physicians. In 1991, the limiting charge was $125 \%$ of the recognized payment amount; this limit decreased to $120 \%$ in 1992 and $115 \%$ in 1993 . Since the fee for non-participants is $95 \%$ of the fee for participants, physicians have effectively been permitted to bill their patients only $9.25 \%$ above the Medicare participating physician fee since 1993. New York implemented a more stringent limiting charge of $115 \%$ of the recognized payment amount beginning in 1991; New York's limiting charge fell to $110 \%$ in 1992 . Table 1 provides a summary of the law changes and indicates the share of Medicare beneficiaries who were impacted by any type of balance billing restriction in each year. Figure 1 shows the average per-beneficiary balance billing liability for each year between 1977 and 1993. As the figure illustrates, average per-beneficiary balance bills were rising through the early 1980s, before beginning a decline that continued through 1993 . 
Advocates argued that balance billing restrictions would lead to greater access to medical care for the elderly. In particular, they claimed that the elderly would be more likely to obtain necessary medical care if they did not face any uncertainty about out-of-pocket costs. Uncertainty arises from the fact that patients do not always have the option to choose their specialists and from the fact that an individual physician treating an individual patient may choose to accept assignment on one visit, but not on another (GAO, 1989; Physician Payment Review Commission (PPRC), 1988). In addition, advocates pointed out that roughly half of Medicare beneficiaries did not understand the term "assignment" and approximately three-quarters had not heard of the Participating Physician and Supplier program (GAO, 1989). Given these facts, advocates argued that it was unreasonable to expect beneficiaries to lower their out-of-pocket costs by finding and using a participating physician. Thus, they predicted that restrictions on balance billing would increase access to care by the elderly.

Opponents argued that, as a form of price ceilings, balance billing restrictions would have the opposite effect, reducing access to care for Medicare beneficiaries. In particular, they suggested that physicians would be less willing to treat Medicare patients and, when balance billing regulations had been enacted in only a few states, physicians might move to states with less restrictive policies (GAO, 1989). In 1987, William McDermott of the Massachusetts Medical Society said that, in response to Massachusetts' balance billing restriction, "you're going to find a lessening of access for elderly patients" (UPI, 1987). Likewise, Kirk Johnson of the American Medical Association suggested that, under such policies, beneficiaries might receive inferior treatment (Wald, 1987). Concern about the adverse effects of balance billing restrictions was sufficiently strong that, when the Puget 
Sound Council of Senior Citizens sponsored a public referendum in Washington to ban balance billing, the state chapter of the AARP opposed it (PPRC, 1988).

As mentioned above, empirical evidence on the effects of balance billing restrictions is limited. The GAO completed a study in 1989 , based on the initial evidence from restrictions in Massachusetts, Connecticut, Rhode Island and Vermont. In an analysis of Medicare claims for these states between 1985 and 1987, the GAO found evidence of a decrease in out-

of-pocket spending by the elderly. However, the authors concluded that insufficient time had passed since the policies had been implemented to draw any conclusions about physician behavior. The short length of time between policy implementation and evaluation is a particular concern if we believe that long-run physician responses may be stronger than short-run responses. In this paper, I provide evidence on longer-term responses, using data that extends as far as 10 years beyond the first policy change in Massachusetts.

\section{Theoretical Framework}

Modeling the physician as an income-maximizer provides insight into how physicians might respond to restrictions on balance billing. Assume that a physician acts to maximize his income:

$$
I=p\left(Q_{\operatorname{Pr} i v}, f\right) \cdot Q_{\operatorname{Pr} i v}+f \cdot\left(Q_{\text {Total }}-Q_{\operatorname{Pr} i v}\right)-c\left(Q_{\text {Total }}\right) \cdot Q_{\text {Total }}
$$

where $p$ is the price charged to "private" (non-Medicare and Medicare non-assigned) patients, $Q_{P r i v}$ is the number of "private" (non-Medicare and Medicare non-assigned) patients, $f$ is the Medicare fee, $Q_{\text {Total }}$ is the total number of patients, and $c$ is the cost of treating a patient. Note that $Q_{P r i v}$ is composed of two distinct groups of patients: nonMedicare patients and Medicare non-assigned patients. When balance billing is incorporated 
in this model, one of the two groups - the Medicare non-assigned - will be shifted out of $Q_{\text {Priv }}$

I assume that the cost of seeing patients increases with the number of patients seen, due to actual costs of treatment and the physician's demand for leisure (i.e. $d c / d Q_{T o t}>0$ ). I also assume that the private price increases with Medicare fee (i.e. $d p / d f>0$ ), which reflects the fact that Medicare non-assigned patients are concerned only about their out-of-pocket costs. If a non-assigned Medicare patient has met his deductible, his net out-of-pocket cost is the standard copayment $(20 \%$ of the Medicare fee, $f$ ) plus the balance bill $(p-f)$. That is, the net price to a non-assigned Medicare patient is $p-\left(0.8^{*} f\right)$. Since an increased Medicare fee offsets part of the net out-of-pocket cost, non-assigned Medicare patients are willing to pay higher $p$ to remain at the same level of out-of-pocket cost for any quantity of services. To the extent that the private market is dominated by non-assigned Medicare patients, $d p / d f$ may be close to 0.8 ; to the extent that the private market is dominated by non-Medicare patients, $d p / d f$ will be close to zero. Finally, I assume that the physician faces a downward sloping demand curve for private patient care (i.e. $d p / d Q_{\text {Priv }}<0$ ). This assumption reflects the notion that physicians are monopolistic competitors due to product differentiation.

The physician chooses $\mathrm{Q}_{\text {Priv }}$ and $\mathrm{Q}_{\text {Total }}$ to maximize income. The two first-order conditions are:

$$
\frac{d I}{d Q_{\operatorname{Pr} i v}}=p+Q_{\operatorname{Pr} i v} \frac{d p}{d Q_{\operatorname{Pr} i v}}-f=0
$$

and:

$$
\frac{d I}{d Q_{\text {Total }}}=f-c-Q_{\text {Total }} \frac{d c}{d Q_{\text {Total }}}=0
$$


The first of these conditions, equation (2), indicates that a physician will provide services to private patients until the marginal revenue from an additional private patient $\left(p+Q_{\operatorname{Pr} i v} \frac{d p}{d Q_{\operatorname{Pr} i v}}\right)$ is equal to the marginal revenue $(f)$ from an additional Medicare assigned patient. Rearranging equation (2) yields the elasticity of price with respect to Qpriv:

$$
\eta_{p}=\frac{d P}{d Q_{\mathrm{Pr} i v}} \cdot \frac{Q_{\mathrm{Pr} i v}}{P}=\frac{f-p}{p}
$$

This equation implies that the elasticity increases with $f$ and decreases with $p$.

Equation (3) indicates that the physician will provide services to patients until the marginal cost of providing services to an additional patient $\left(c+Q_{\text {Total }} \frac{d c}{d Q_{\text {Total }}}\right)$ is equal to the marginal revenue $(f)$ from providing services to an additional patient. Rearranging this firstorder condition, we have the elasticity of cost with respect to $Q_{\text {Total }}$ :

$$
\eta_{c}=\frac{d c}{d Q_{\text {Total }}} \cdot \frac{Q_{\text {Total }}}{c}=\frac{f-c}{c}
$$

Figure 2, which follows earlier work on Medicare by Mitchell and Cromwell (1982), Paringer (1982) and Zuckerman and Holahan (1991), graphically represents the physician's maximization problem. As above, he stops seeing private patients when the marginal revenue from private patients is equal to the marginal revenue of Medicare assigned patients; thus, $Q_{P r i v}$ is established at the point where the two marginal revenue curves cross and the price for private patients is set by the demand curve at that point. The point at which the physician stops seeing Medicare assigned patients is given by the intersection of the marginal cost and marginal Medicare revenue curves. It is possible for the physician's marginal cost curve to be sufficiently high that it intersects the private marginal revenue curve at a price 
above the Medicare marginal revenue curve, as shown in Figure 3. In such a case, the physician chooses never to treat assigned Medicare patients; his only Medicare patients will be those patients who are willing to be balance-billed.

What does this theoretical framework predict about the effect of restricting balance billing? In the extreme case of banning any balance billing of Medicare beneficiaries, the policy can be viewed as restricting the demand for physician services by private patients at any given price level. Specifically, a ban on balance billing would force the Medicare nonassigned component of $\mathrm{QPriv}_{\text {po }}$ join the Medicare assigned patients. This would decrease the demand by private patients and increase the demand by Medicare assigned patients. Assuming that the physician was previously treating at least some Medicare assigned patients, this change will decrease the number of private patients seen by a physician, without changing the total number of patients seen. In other words, the previously non-assigned Medicare patients will simply become assigned Medicare patients and the overall quantity of care will remain the same. Figure 4 illustrates the change.

If the physician was not previously seeing Medicare assigned patients (but was seeing Medicare non-assigned patients at private-market prices), he may respond to balance billing restrictions by treating fewer patients in total. As shown in Figure 3, such a physician has a sufficiently steep marginal cost curve that, in the pre-policy period, his marginal cost curve intersected the downward-sloping (private) segment of the marginal revenue curve, rather than the horizontal (Medicare assigned) segment of the marginal revenue curve. After the imposition of balance billing restrictions, he - like other physicians - faces downward shifts in the private demand and private marginal revenue curves; unlike other doctors, he 
determines $Q_{\text {Total }}$ by the intersection of the private marginal revenue and marginal cost curves and, therefore, may decrease $Q_{\text {Total }}$ in response to the restrictions.

Implementation of balance billing restrictions in the United States generally occurred in an environment where Medicare fees were falling relative to prices that could be charged to private payers. Indeed, part of the motivation for restricting balance billing was concern that, as the federal government decreased reimbursement rates to physicians, these decreases for physicians would be passed through to Medicare beneficiaries in the form of increases in balance billing. According to the PPRC, Medicare fees in 1991 were 65\%, on average, of the prices that private payers and insurance companies were allowing for the same procedures. This was a decline from 71\% just two years earlier (PPRC, 1991).

Figure 5 illustrates the changes that physicians faced when Medicare balance billing restrictions were imposed. In response to the simultaneous decline in Medicare fees and decline in demand for non-assigned Medicare services, this model suggests that physicians would treat fewer "private" patients (and at a lower price) and would treat fewer total patients. Depending on the relative magnitudes of the declines in private demand and in Medicare fees, a physician might increase or decrease the number of assigned Medicare patients that he treats. Thus, the model could provide theoretical support for either the advocates or opponents of balance billing restrictions, depending on the parameters of the model.

One caveat to the preceding model is that it assumes that demand does not constrain the physician's choice of the quantity of services provided. This assumption may be unrealistic, because beneficiaries always face out-of-pocket costs and, therefore, are unlikely to have unlimited demand for physician services. If demand were a constraint in the initial pre- 
policy equilibrium, restrictions on balance billing could cause demand to expand due to the fact that beneficiaries face decreased out-of-pocket costs of obtaining physician services. As a result, the equilibrium quantity of services provided could increase. This scenario roughly corresponds to the perspective of advocates of the balance billing restriction policies.

The overall insight from the theoretical framework is that the impact of balance billing restrictions is ambiguous. Theoretical work by other authors adds more ambiguities. Several papers point to ways that the simple income-maximizing framework could be modified. These papers raise substantial questions about the appropriate model of physician behavior, but do not provide a clear consensus on the predicted effects of price controls, in general, or balance billing restrictions, in particular. For example, Feldman and Sloan (1988) and Glazer and McGuire (1993) use models that incorporate both quantity and quality of care as choice variables. Wedig, Mitchell, and Cromwell (1989) highlight the potential issue of income targeting by physicians, which could create a scenario where price controls lead to increases in the quantity and quality of services. In addition, Wedig, Mitchell and Cromwell (1989), McGuire (2000), and numerous other authors have discussed the possibility of demand inducement by physicians, which could also cause price controls to lead to increases in quantity or quality of care. In short, theoretical models of physician behavior have raised important issues that increase the ambiguity of the predictions in the previous section. The goal of this paper, therefore, is to provide some empirical evidence about the direction and magnitude of the effect of balance billing restrictions. 


\section{Data}

For my empirical analysis of the effects of balance billing restrictions, I turn to several survey data sets. Unfortunately, no single data source provides information on out-of-pocket expenditures, quantity of medical care and quality of medical care during the time period that corresponds to balance billing policy changes. As a result, I use three different data sets, each of which provides evidence on an important outcome that may be affected by balance billing restrictions. In addition, I use aggregate data on the number of physicians of different specialties who are practicing in each state and year, in order to assess general equilibrium effects of the restrictions.

The first survey data set that I use is the Consumer Expenditure Survey (CEX), which provides detailed quarterly household expenditure information. I use CEX data from 1984 to 1996, which allows me to analyze the effects of restrictions on out-of-pocket medical expenditures by households with at least one elderly (aged 65 or over) member. I exclude households that are income-eligible for Medicaid, because there may be differences in Medicaid policy across states and over time that could affect my dependent variables. A disadvantage of the CEX is that state identifiers are not available for smaller states. As a result, my sample includes only 38 states and the District of Columbia. In particular, two of the states that passed balance billing restrictions in 1987, Rhode Island and Vermont, are not represented in my CEX data set. The final sample includes 33,840 observations on elderly households. Categories of expenditures in the CEX are very detailed, so I am able to separately analyze expenditures on physician services, prescription drugs, hospital services and numerous other components of out-of-pocket medical spending. In addition, the CEX 
provides data on household income, which permits analysis of the differential effects of balance billing restrictions by income level.

The National Health Interview Survey (NHIS) provides annual data about the health care utilization of individuals. I use the 1984-1994 data sets to provide evidence about the effects of balance billing restrictions on health care utilization among Medicare beneficiaries. I use two key variables from this survey as dependent variables in my analysis: the number of doctor visits in the past 12 months and the number of doctor visits in the two weeks before the interview. The NHIS provides additional details about any visits in the previous two weeks, including the type of doctor visited. I utilize this additional information in my analysis to determine whether balance billing restrictions differentially changed access to any particular physician specialty. I include all individuals aged 65 and older in my sample, except for individuals who are income-eligible for Medicaid. The resulting data set includes 90,598 observations.

Finally, I use the National Ambulatory Medical Care Survey (NAMCS), which provides data on a sample of doctor visits. This data set includes information on the length of the doctor visit and any plans for a follow-up to the visit; I use these variables as proxies for quality of care in my analysis. The NAMCS also includes detailed information on the reason for the doctor visit as well as patient demographics, which are used as control variables in my empirical analysis. Patient income and, more importantly, state identifiers are not available for the NAMCS during this period, so I implement a different empirical strategy when I use this data. My analysis includes survey data for the years 1985 and 1989 through 1994, including observations for patients aged 55 and over; no data were collected from 1986 to 1988. Because all of the states that initiated their own balance billing 
restrictions before the federal restrictions were implemented in1991 are located in the northeast and I am unable to identify these states due to the lack of state identifiers, I exclude observations from the northeast of the United States and rely on an age-based identification strategy, as explained below. The resulting data set includes observations on 52,636 visits by patients aged 65 or over and 23,201 visits by patients between the ages of 55 and 64 .

\section{Empirical Strategy}

To identify the effects of balance billing restrictions, I exploit variation in balance billing policy across states and over time. The two primary control groups for the Medicare beneficiaries who are affected by balance billing restrictions include:

1) Beneficiaries of the same age and in the same state, but in earlier years, who are not yet affected by restrictions.

2) Beneficiaries of the same age and in the same year, but in states that are not affected by restrictions.

The independent variable of interest in the CEX and NHIS regressions is a dummy variable for being in a state and year with a balance billing restriction in place. I control separately for the direct effects of state and year, and rely on the interaction for identification. The basic regression takes the following form:

(6) $Y_{i s t}=\alpha+\delta$ Re striction $_{s t}+X_{i s t} \beta+\sum_{s} \gamma_{s}$ State $_{s}+\sum_{t} \gamma_{t}$ Year $_{t}+\sum_{s} \phi_{s}$ State $_{s} *$ Trend $_{t}+\varepsilon_{\text {ist }}$ where $Y_{i s t}$ is a dependent variable for individual $i$ in state $s$ and year $t$. Dependent variables include measures of out-of-pocket expenditures for physician services in the CEX regressions and quantity of services in the NHIS regressions. Restriction st $_{\text {is }}$ a dummy variable that equals one for any person who lives in a state and year with a balance billing 
restriction in place. State $s_{s}$ and Year $_{t}$ are fixed state and year effects, respectively, and State $_{s}{ }^{*} \operatorname{Trend}_{t}$ is a state-specific linear time trend. $X_{i s t}$ is a vector of covariates, which includes age group, gender, marital status, race, education, and income categories. The CEX regressions include additional controls for quarter of interview and size of consumption unit.

\section{Empirical Results}

\subsection{Consumer Expenditure Survey}

Summary statistics for the CEX are shown in Table 2. Simple cross-tabulations of physician services expenditures suggest that Medicare beneficiaries in states and years with balance billing restrictions spent less on physician services than beneficiaries in other states. Elderly households in states and years with balance billing restrictions spent an average of $\$ 43$ per quarter on physician services, whereas households in states and years without balance billing restrictions spent an average of $\$ 85 .^{3}$ Regression results provide a more formal confirmation of these suggestive cross-tabulations.

The first set of regression results from the CEX is shown in Table 3 and indicates a significant, negative effect of balance billing restrictions on physician and total medical services expenditures. Specifically, I find a quarterly decrease in out-of-pocket household expenditures for physician services of about $\$ 30$ for the treatment group. This coefficient is consistent with the aggregate data, which suggests that annual per-beneficiary balance billing liability decreased by about $\$ 89$ between 1985 and 1995 (U.S. Congress, 1994). Out-ofpocket expenditures on "total medical expenses," which include physician services and numerous other categories of services, also show a significant effect. As a share of

\footnotetext{
${ }^{3}$ Dollar amounts are in real (1999) dollars.
} 
expenditures for physician services, the $\$ 30$ impact of balance billing restrictions is a substantial 44\%; as a share of total medical expenditures, the restrictions cause an $8 \%$ decline. The other categories of expenditures generally show no significant effects. Those categories that do have significant coefficients or large, insignificant coefficients are categories of expenditures that are also likely to have been impacted by the balance billing restrictions, such as hospital care and dental services. ${ }^{4}$

While not shown here, I find that these results are robust to the inclusion of an additional control group, non-elderly households with heads between the ages of 55 and 64 , in a triple-difference framework. This specification has the advantage of controlling for secular trends that may affect patterns of medical care. However, the theoretical framework raises the possibility that this additional "unaffected" group may have experienced some changes in medical care utilization due to changes in the Medicare market. For example, the declining Medicare fee, relative to private fees, during this period could have led to an increase in provision of care to the non-elderly. As a practical matter, however, the inclusion of this additional control group has little impact on my main empirical results.

The finding that balance billing restrictions decrease expenditures for physician services by $44 \%$ among elderly households raises the issue of the distributional consequences of the restrictions. While these restrictions may have been enacted to protect the elderly from high out-of-pocket medical expenses, they presumably also protected some beneficiaries with high incomes who did not have an obvious need for protection against balance billing restrictions. Table 4 provides evidence on this issue, derived from regressions that interact a

\footnotetext{
${ }^{4}$ Balance bills from oral surgeons were, on average, equal to $24 \%$ of the Medicare allowed charges in 1990 (Helbing and Petrie, 1992).
} 
dummy variable for "high" income with Restriction ${ }_{s t}{ }^{5}$ "High" income is defined as any income over $\$ 23,145$ (in real 1999 dollars), the median for the elderly households in the data set. A significant, negative coefficient on the interaction term would imply that high-income beneficiaries benefited more from the restrictions. The results in Table 4 suggest that highincome households experienced a significantly larger reduction in the level of out-of-pocket physician expenditures. While mean quarterly physician expenditures are higher in highincome households than in low-income households, the reduction in out-of-pocket expenditures as a share of mean expenditures for high-income households (46\%) was greater than the reduction for low-income households (36\%). However, these findings are not robust to using total medical expenditures as the dependent variable or to the addition of the nonelderly control group. Therefore, overall, I conclude that balance billing restrictions decreased the out-of-pocket liability of elderly households, but did not necessarily benefit high-income elderly households more than low-income households.

\subsection{National Health Interview Survey}

I next turn to the NHIS to determine effects of balance billing restrictions on the quantity of care provided to elderly beneficiaries. Table 5 shows summary statistics and Table 6 presents evidence from OLS and Probit regressions about how balance billing restrictions affected the quantity of physician care received by elderly individuals. ${ }^{6}$ The regression coefficients in the first 2 rows provide no evidence that Medicare beneficiaries

\footnotetext{
${ }^{5}$ These regressions also control directly for having high income.

${ }^{6}$ Since the dependent variables count the number of doctor visits of various types, a count model might seem like a natural alternative to OLS or Probit. However, $76 \%$ of observations report 0 visits of any type in the past 2 weeks and $17 \%$ report 1 visit; therefore, the decision to have any visit, rather than the number of visits, appears to be the margin that is most likely to be affected by balance billing restrictions for almost all of the dependent variables. The one exception is "visits in the past 12 months"; negative binomial regressions using this dependent variable yield results that are similar to those shown in Table 6.
} 
received any more or less care as a result of balance billing restrictions. The point estimates for the number of doctor visits are all positive, but statistically insignificant. The confidence intervals for the OLS coefficient on the number of doctor visits in the past 12 months allow for the possibility that balance billing restrictions decreased the number of visits by no more than $11 \%$ and increased the number of visits by no more than $16 \%$ relative to the mean. In short, the restrictions do not appear to have affected the quantity of care received by Medicare beneficiaries but, if they did affect the quantity, the effect was relatively small.

Since Helbing and Petrie (1992) reported wide variation among specialties in balance billing patterns, I next consider the possibility that balance billing restrictions had different impacts on different types of specialties. To capture differential effects by specialty, Table 6 reports results from separate regressions for the number of visits in the past 2 weeks to six different types of physicians. Average 1990 balance billing as a share of the Medicare fee is shown in the last column of the table for each specialty. The results do not suggest that balance billing restrictions affected the quantity of care received, even for physicians with relatively high average balance bills.

\subsection{National Ambulatory Medical Care Survey}

Table 7 shows summary statistics for the NAMCS sample of doctor visits. The dependent variables in this data set include the duration of the doctor visit, as reported by the physician, and the follow-up plans that were arranged. I interpret these variables as proxies for the quality of care received. The statistics are shown separately for the 55-64 year old control group in column 1, for the 65-75 year-old treatment group in column 2, and the 75 and older treatment group in column 3. The 75 and older patients are excluded from some of 
the regressions in order to make the treatment and control groups more comparable. As the summary statistics show, excluding the oldest age groups creates a sample that appears to be more homogeneous.

The identification strategy for the NAMCS differs from the basic regression framework because state identifiers are not available in the NAMCS. In this case, the potential control groups are limited to:

1) Beneficiaries of the same age, but in earlier years, who are not yet affected by the federal restrictions.

2) Patients of slightly younger ages (55-64) who are not Medicare beneficiaries and are therefore not affected by balance billing restrictions.

While it is not necessarily reasonable to assume that a 55-year-old would have a doctor's appointment of the same length as a 74-year-old, this assumption is more reasonable if the 55-year-old and the 74-year-old are suffering from the same health problem. So, although it is impossible to use geographic variation to identify the impact of balance billing restrictions, the use of age variation is more palatable in the NAMCS, since the data provides detailed information about reasons for physician visits.

The framework for analyzing the effects of balance billing on Medicare beneficiaries in the NAMCS is as follows:

$$
Y_{\text {ait }}=\alpha+\gamma \text { Age65 }_{a}+\delta \text { Age65 }_{a} * \text { Post }_{t}+X_{\text {ait }} \beta+\sum_{t} \gamma_{t} \text { Year }_{t}+\varepsilon_{\text {ait }}
$$

where $Y_{\text {ait }}$ measures a dependent variable for doctor visit $i$ provided to a patient in age group $a$ in year $t$. In this empirical framework, $A g e 65_{a}$ is a dummy variable for the patient being aged 65 or older and Post $t_{t}$ is a dummy variable for years after 1990. The coefficient of interest is $\delta$, which represents the effect of the patient being older than age 65 in the post- 
policy, as opposed to the pre-policy, period. $X_{\text {ait }}$ is a vector of covariates, which includes the physician's specialty and the primary reason for the patient's visit. The identifying assumption is that, conditional on the reason for a visit and other covariates, there are no differential trends in the dependent variable among the two age groups. An alternative regression, which may reduce concerns about differential trends in the age groups, excludes observations over the age of 74 who are likely to be more different from the 55-64 age group.

Replicating this identification strategy as closely as possible in the CEX yields results that are similar to the results shown in Table 3. In particular, I use CEX data, but exclude observations in the Northeast and control only for sex, age, race, year and quarter. The effect of the balance billing restrictions is identified using an interaction between a dummy variable for being an elderly household and a dummy variable for being post-1990. The results indicate a statistically significant decline of $\$ 23.78$ in quarterly expenditures for physician services and a decline of $\$ 39.37$, significant at the $10 \%$ level, in total quarterly expenditures for medical care. The fact that results in the CEX using this alternative identification strategy are similar to results reported in Table 3, using the preferred geographic identification strategy, suggest that this alternative identification strategy may successfully capture the impact of the balance billing restrictions.

The results in Table 8 do not show substantial evidence of changes in the quality of health care provision. The only significant results indicate that physicians are less likely to arrange a follow-up telephone call for the older age group after 1990. The coefficient of -.006 represents a $20 \%$ decline in follow-up phone calls relative to the mean. This result is present in the full sample as well as the younger, more homogeneous sub-sample. The various types of follow-up plans are not mutually exclusive, so it is reasonable that there is 
no significant offsetting increase in another category of follow-up. This result suggests a small, negative impact on quality of care for Medicare beneficiaries after balance billing restrictions were imposed.

In Table 9, I take advantage of variation in physician specialty. A physician with higher average pre-policy balance bills may react more strongly to balance billing restrictions than a physician with low balance bills, because the physician with larger pre-policy balance bills would face a larger percentage decline in marginal reimbursement for care to Medicare beneficiaries. To capture this effect, I interact the specialty-specific balance billing rates, based on Helbing and Petrie (1992), with Age65 $_{i t}{ }^{*}$ Post $_{t}$. The coefficients on these interaction terms are always insignificant but the standard errors are so large that it is impossible to rule out the possibility of large effects. The results in Table 9 are therefore inconclusive. Taken together, the only evidence of changes in care quality from the NAMCS suggests a decrease in follow-up phone calls, but no other apparent reduction in care quality.

\subsection{Effects on Aggregate Physician Supply}

One final and important issue is the general equilibrium effects of balance billing restrictions. The restrictions could have led to a decrease in the supply of physicians through numerous mechanisms, including increases in physician retirement rates, physician migration between states or slowdowns in physician immigration from foreign countries. Opponents of balance billing restrictions suggested that the supply of physicians would, in fact, decline as a result of these policies.

Using aggregate data from numerous editions of the American Medical Association's publication, Physician Characteristics and Distribution, I consider whether there is an 
impact of balance billing policies on the number of physicians per 1000 residents in a given state. Using data from 1981 to 1993 on the number of doctors of each specialty in each state and year, I test whether the supply of physicians in specialties that historically charged relatively higher balance bills was more likely to decline in states with balance billing restrictions. I interact the balance billing rate of each specialty with Restriction st $_{\text {. The effect }}$ of balance billing restrictions is, therefore, identified from the interaction of state, year and physician specialty. The regression model is saturated, with controls for state*year, specialty*year, and state*specialty. Specialties observed include: general surgeons, internists, neurosurgeons, obstetrician-gynecologists, ophthalmologists, orthopedists, pediatricians, plastic surgeons, psychiatrists, radiologists and thoracic surgeons. Of these specialties, pediatricians had the lowest level of balance billing, with an average balance bill that was $4 \%$ of the Medicare approved charge in 1990, and anesthesiologists had the highest level of balance billing, with an average balance bill that was $24 \%$ of the Medicare approved charge in 1990.

The results in the first column of Table 10 provide little evidence of a decline in the number of doctors per 1,000 residents in high balance billing specialties relative to low balance billing specialties in states and years with restrictions. The results in the second column, which allow for the effect of the restrictions to vary over time, provide some evidence of a decrease in physicians per 1,000 residents, beginning two years after policy implementation, but the coefficient is significant at only the $10 \%$ level. It seems reasonable that physician labor supply would respond with a multiple-year lag. The coefficient is not statistically significant, but suggests that a specialty that had average balance bills that were $10 \%$ larger as a share of the Medicare allowed charge in 1990 experienced a relative decline 
of 5 physicians per million residents. Relative to the mean of 105 physicians per million residents, this effect is relatively small.

\subsection{Policy Endogeneity Concerns and Sensitivity Tests}

The possibility of policy endogeneity is a source of concern for my identification strategy. For example, it is possible that balance billing restrictions were first implemented in states that had particular reasons to be concerned about the financial liabilities of their elderly residents or in states where initial assignment rates were sufficiently high that mandatory assignment would be a less binding constraint. Pre-policy assignment rates in states that passed restrictions varied widely, from $58 \%$ in Connecticut to $94 \%$ in Massachusetts and Rhode Island. However, the mean assignment rate among states that passed restrictions, at 78\%, was higher than the national average of $60 \%$ (U.S. Congress, 1994). This fact suggests that balance billing restrictions were less of a constraint in states that first passed restrictions. Consequently, my findings may underestimate the impact of balance billing restrictions in a typical state.

In addition to restricting balance billing, OBRA 89 created the Medicare Fee Schedule, which was implemented in 1992. The new fee schedule changed the level of reimbursement that was received by physicians, depending on their specialties and locations. In general, the Medicare fee changes favored primary care physicians and rural physicians. If these price changes were correlated with changes in balance billing restrictions, my estimates of the impact of balance billing could be biased. In order to address this concern, I test the sensitivity of my empirical results to controlling for the percentage change in Medicare payment rates between 1991 and 1993 by state and by primary care status (U.S. Congress, 
1994). As an additional specification check, I run my regressions without post-1991 data.

My empirical results are not substantively changed by either specification check.

\section{Conclusion}

How physicians respond to differential payment rates across different types of patients is an important issue for the design of reimbursement policy. Concerns about physician responses to such differences have arisen in the context of Medicare balance billing restrictions and, more recently, in the context of "concierge physicians," who charge out-ofpocket fees substantially in excess of normal reimbursement limits. Most recently, the New York Times reported that a physician paid a $\$ 53,400$ settlement to the government for charging Medicare beneficiaries a $\$ 600$ fee in exchange for extra services, such as round-theclock access to the physician and coordination of care with other providers (Pear, 2004). Advocates and opponents have offered divergent views of the implications of charging such fees, with little empirical evidence to substantiate these views. In the historical context of balance billing restrictions, policy advocates felt that restrictions would improve access to care for the elderly, whereas opponents felt that restrictions would hinder access to care.

In this paper, I use variation in the timing of restrictions in different states to identify the impact of balance billing restrictions. I find little empirical evidence that physicians changed their behavior in response to the balance billing restrictions. However, I do find suggestive evidence of a decline in follow-up telephone calls associated with the restrictions. Overall, these findings do not provide strong support for the views of either the advocates or the opponents of balance billing restrictions. In the context of the recent debate about 
concierge physicians, these findings suggest that concerns about decreased access to care among individuals who can’t afford additional fees may be overstated.

The empirical results do, however, suggest a decline in out-of-pocket spending of roughly $\$ 120$ per elderly household per year, which amounts to an $8 \%$ decline in overall medical spending per household in the data. There is some evidence that the reduction in spending was concentrated among high-income beneficiaries, but this evidence is not robust to alternative specifications. Regardless, this decline in spending represents a transfer from physicians to Medicare patients and the welfare implications of the policy change depend primarily on how this transfer affects the social welfare function 


\section{References}

American Medical Association. Physician Characteristics and Distribution.Chicago: American Medical Association, various issues.

Feldman, Roger, and Frank Sloan (1988). "Competition Among Physicians, Revisited", Journal of Health Politics, Policy and Law 13: 239-261.

Glazer, Jacob and Thomas G. McGuire (1993). "Should Physicians Be Permitted to 'Balance Bill' Patients?" Journal of Health Economics 11: 239-258.

Health Care Financing Administration (2000). Health Care Financing Review, Medicare and Medicaid Statistical Supplement.

Helbing, Charles and John T. Petrie (1992). "Supplementary Medical Insurance Benefit for Physician and Supplier Services," Health Care Financing Review Annual Supplement: 149-170.

McGuire, Thomas G (2000). "Physician Agency" in A. J. Culyer and J.P. Newhouse, eds, Handbook of Health Economics, Volume 1 (New York: Elsevier): 461-536.

Mitchell, Janet B. and Jerry Cromwell (1982). "Physician Behavior Under the Medicare Assignment Option." Journal of Health Economics 1: 245-264.

New York Times, “Boutique Medicine,” January 17, 2002.

Paringer, Lynn (1980). "The Medicare Assignment Rates of Physicians: Their Responses to Changes in Reimbursement Policy." Health Care Financing Review 1: 75-89.

Pear, Robert (2004). "U.S. Warns About Care Doctors Offer for Extra Fees," New York Times, April 13, 2004.

Physician Payment Review Commission (1988), Annual Report to Congress, 1988, Washington D.C.

Physician Payment Review Commission (1991), Annual Report to Congress, 1991, Washington D.C.

Rice, Thomas (1984) "Determinants of Physician Assignment Rates by Type of Service", Health Care Financing Review 5(4): 33-42.

United Press International (1987), “Massachusetts Doctors Decry Supreme Court Ruling," October 14, 1987.

United State Congress, Committee on Ways and Means (1994). Green Book 1994: 
Background Material on Programs Under the Jurisdiction of the Committee on Ways and Means, Washington D.C.: GPO.

U.S. General Accounting Office, Impact of State Mandatory Assignment Programs on Beneficiaries, HRD-89-128, September 1989.

Wald, Matthew (1987), "U.S. Court Ruling Could Spur State Caps on Medicare Fees," New York Times, April 8: A1.

Wedig, G., J. B. Mitchell and J. Cromwell (1989). "Can Optimal Physician Behavior be Obtained Using Price Controls?” Journal of Health Politics, Policy and Law 14(3): 601-620.

Zuckerman, S. and J. Holahan (1991). "The Role of Balance Billing in Medicare Physician Payment Reform" in H. E. Frech III, ed., Regulating Doctors' Fees: Competition, Benefits and Controls Under Medicare (Washington, DC: AEI Press): 143-169. 
Table 1: Implementation of Balance Billing Restrictions

\begin{tabular}{ccc}
\hline Year & States implementing a policy & $\begin{array}{c}\text { Percentage of all Medicare } \\
\text { enrollees affected by a restriction }\end{array}$ \\
\hline 1986 & Massachusetts & $2.7 \%$ \\
1987 & Connecticut, Rhode Island, Vermont & $4.8 \%$ \\
1990 & Pennsylvania & $10.5 \%$ \\
1991 & All remaining states & $100 \%$ \\
\hline
\end{tabular}


Table 2: CEX Summary Statistics

\begin{tabular}{|c|c|c|}
\hline Variable & Mean & Standard deviation \\
\hline Physician services expenditures & 65.90 & 284.68 \\
\hline Prescription drugs expenditures & 113.83 & 206.73 \\
\hline Hospital services expenditures & 29.06 & 558.08 \\
\hline Eye exams, treatment and surgery & 13.62 & 105.84 \\
\hline Medical supplies & 20.11 & 81.93 \\
\hline Dental services & 68.46 & 284.70 \\
\hline Labs, tests, x-rays & 10.16 & 81.59 \\
\hline Care in nursing homes, ambulances, etc & 28.74 & 472.17 \\
\hline Other medical services expenditures & 23.65 & 395.97 \\
\hline Total medical services expenditures & 373.53 & 1058.24 \\
\hline Restriction & .449 & .497 \\
\hline Male & .581 & .493 \\
\hline Married & .516 & .500 \\
\hline Age of household head & 71.53 & 9.68 \\
\hline Real household income & 32,619 & 29,890 \\
\hline Household size & 1.98 & 1.19 \\
\hline Observations & \multicolumn{2}{|c|}{33,840} \\
\hline
\end{tabular}


Table 3: Medical Expenditures

\begin{tabular}{|c|c|c|c|c|}
\hline $\begin{array}{l}\text { Dependent variable } \\
\text { (in } 1999 \text { \$) }\end{array}$ & $\begin{array}{c}(1) \\
\text { Expenditures }\end{array}$ & $\begin{array}{c}\text { (2) } \\
\text { Any } \\
\text { expenditures }\end{array}$ & $\begin{array}{c}\text { (3) } \\
\text { Log } \\
\text { expenditures }\end{array}$ & $\begin{array}{c}(4) \\
\text { Expenditures } \\
\text { (median) }\end{array}$ \\
\hline Physician services & $\begin{array}{c}-29.17 * * \\
(8.49)\end{array}$ & $\begin{array}{c}-.052 * * \\
(.020)\end{array}$ & $\begin{array}{c}-.156 * * \\
(.074)\end{array}$ & \\
\hline Prescription drugs & $\begin{array}{l}-16.54 \\
(10.08)\end{array}$ & $\begin{array}{l}-.027 \\
(.033)\end{array}$ & $\begin{array}{l}-.099 \\
(.069)\end{array}$ & \\
\hline Hospital & $\begin{array}{l}-27.89 \\
(20.05)\end{array}$ & $\begin{array}{l}-.011 \\
(.010)\end{array}$ & $\begin{array}{l}-.448^{*} \\
(.262)\end{array}$ & \\
\hline $\begin{array}{l}\text { Eye exams and } \\
\text { treatment }\end{array}$ & $\begin{array}{c}2.53 \\
(2.91)\end{array}$ & $\begin{array}{l}-.004 \\
(.012)\end{array}$ & $\begin{array}{l}-.015 \\
(.096)\end{array}$ & \\
\hline Medical supplies & $\begin{array}{c}-.28 \\
(3.55)\end{array}$ & $\begin{array}{l}.004 \\
(.011)\end{array}$ & $\begin{array}{l}-.017 \\
(.171)\end{array}$ & \\
\hline Dental services & $\begin{array}{l}-32.54 * \\
(16.77)\end{array}$ & $\begin{array}{c}-.035 * * \\
(.015)\end{array}$ & $\begin{array}{l}-.081 \\
(.141)\end{array}$ & \\
\hline Labs, tests, x-rays & $\begin{array}{l}-4.39 \\
(2.71)\end{array}$ & $\begin{array}{l}-.002 \\
(.009)\end{array}$ & $\begin{array}{c}-.445 * * \\
(.163)\end{array}$ & \\
\hline $\begin{array}{l}\text { Care in nursing homes, } \\
\text { ambulances, etc. }\end{array}$ & $\begin{array}{l}-79.70 \\
(69.77)\end{array}$ & $\begin{array}{l}-.011 \\
(.009)\end{array}$ & $\begin{array}{l}-.194 \\
(.530)\end{array}$ & \\
\hline Other expenses & $\begin{array}{l}-11.98 \\
(13.29)\end{array}$ & $\begin{array}{l}.009 \\
(.012)\end{array}$ & $\begin{array}{l}-.109 \\
(.176)\end{array}$ & \\
\hline Total medical expenses & $\begin{array}{l}-199.95^{*} \\
(113.98)\end{array}$ & $\begin{array}{l}-.017 \\
(.014)\end{array}$ & $\begin{array}{c}-.248 * * \\
(.063)\end{array}$ & $\begin{array}{c}-31.57 * * \\
(12.30)\end{array}$ \\
\hline Number of observations & 33,840 & 33,840 & Varies & 33,840 \\
\hline
\end{tabular}




\section{Table 4: Medical Expenditures by income category}

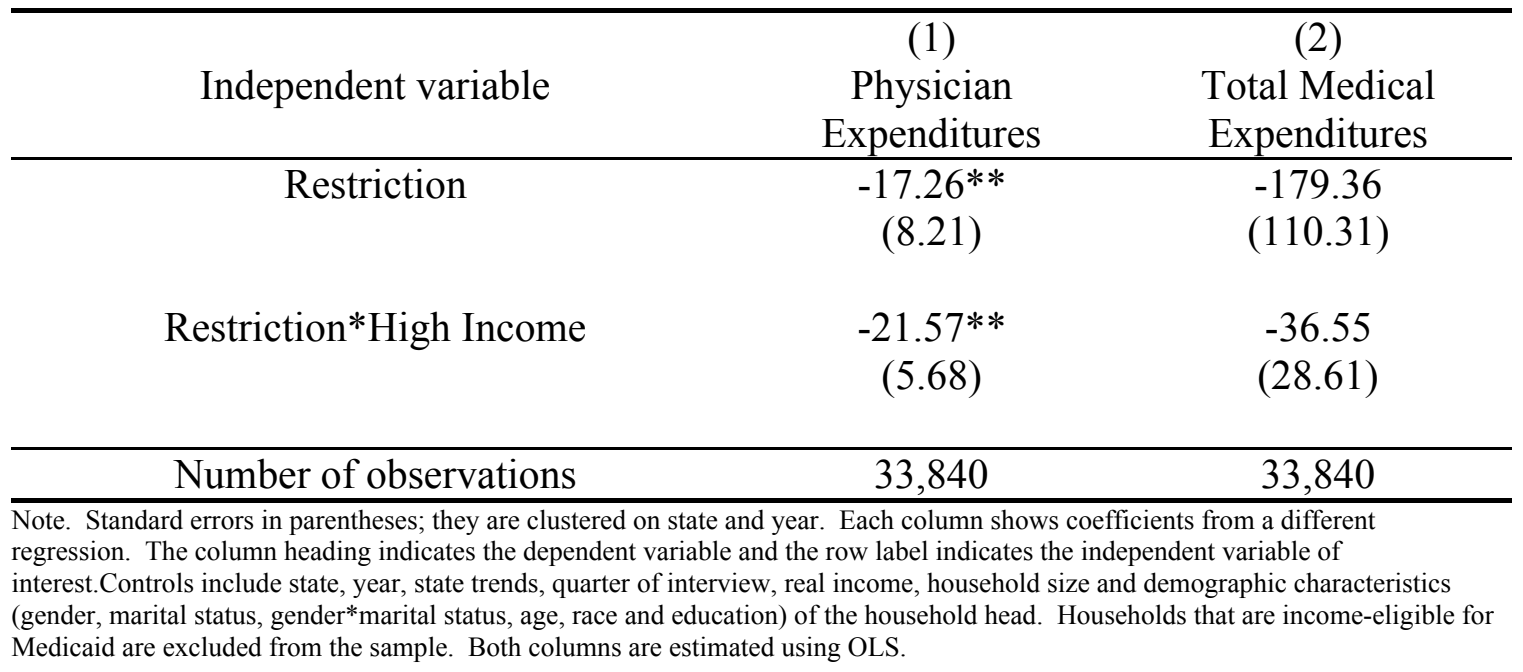


Table 5: NHIS Summary Statistics

\begin{tabular}{lcc}
\hline Variable & Mean & Standard deviation \\
\hline Doctor visits in past 12 months & 6.06 & 14.88 \\
Doctor visits in past 2 weeks & .368 & .971 \\
Ophthalmology visits in 2 weeks & .024 & .187 \\
Internal medicine visits in 2 weeks & .073 & .412 \\
Radiology visits in 2 weeks & .015 & .273 \\
Orthopedic surgery visits in 2 weeks & .014 & .194 \\
General practice visits in 2 weeks & .146 & .540 \\
Psychiatry visits in 2 weeks & .002 & .052 \\
Restriction & .413 & .492 \\
Male & .431 & .495 \\
Married & .590 & .492 \\
Age & 73.85 & 6.25 \\
\hline Observations & & 90,598 \\
\hline
\end{tabular}


Table 6: Quantity of Medical Care

\begin{tabular}{|c|c|c|c|c|c|}
\hline Dependent variable & $\begin{array}{c}\text { (1) } \\
\text { Number of } \\
\text { visits }\end{array}$ & $\begin{array}{c}(2) \\
\text { Any visits }\end{array}$ & $\begin{array}{c}\text { (3) } \\
\text { Number of } \\
\text { visits, } \\
\text { conditional on } \\
\text { any }\end{array}$ & $\begin{array}{c}\text { (4) } \\
\text { Number } \\
\text { of visits } \\
\text { (median) }\end{array}$ & $\begin{array}{l}\quad(5) \\
\text { Balance } \\
\text { billing as } \\
\text { share of } \\
\text { Medicare } \\
\text { fee, } 1990\end{array}$ \\
\hline $\begin{array}{l}\text { Doctor visits in past } \\
12 \text { months }\end{array}$ & $\begin{array}{l}.156 \\
(.420)\end{array}$ & $\begin{array}{l}.005 \\
(.008)\end{array}$ & $\begin{array}{l}.169 \\
(.462)\end{array}$ & $\begin{array}{l}.120 \\
(.096)\end{array}$ & \\
\hline $\begin{array}{c}\text { Doctor visits in past } 2 \\
\text { weeks }\end{array}$ & $\begin{array}{l}.008 \\
(.023)\end{array}$ & $\begin{array}{l}.006 \\
(.012)\end{array}$ & $\begin{array}{l}.010 \\
(.041)\end{array}$ & & \\
\hline $\begin{array}{l}\text { Orthopedic surgery } \\
\text { visits }\end{array}$ & $\begin{array}{l}-.001 \\
(.004)\end{array}$ & $\begin{array}{l}-.0004 \\
(.0011)\end{array}$ & $\begin{array}{l}-.076 \\
(.368)\end{array}$ & & $9.83 \%$ \\
\hline Psychiatry visits & $\begin{array}{l}-.0001 \\
(.0008)\end{array}$ & $\begin{array}{l}-.0001 \\
(.0001)\end{array}$ & $\begin{array}{l}.090 \\
(.701)\end{array}$ & & $7.03 \%$ \\
\hline $\begin{array}{l}\text { Internal medicine } \\
\text { visits }\end{array}$ & $\begin{array}{l}-.007 \\
(.008)\end{array}$ & $\begin{array}{c}-.009 * * \\
(.004)\end{array}$ & $\begin{array}{l}.164 \\
(.106)\end{array}$ & & $6.58 \%$ \\
\hline General practice visits & $\begin{array}{l}-.005 \\
(.010)\end{array}$ & $\begin{array}{c}.0001 \\
(.0075)\end{array}$ & $\begin{array}{l}-.043 \\
(.045)\end{array}$ & & $6.56 \%$ \\
\hline Ophthalmologist visits & $\begin{array}{l}-.004 \\
(.003)\end{array}$ & $\begin{array}{l}-.002 \\
(.002)\end{array}$ & $\begin{array}{l}.015 \\
(.073)\end{array}$ & & $4.17 \%$ \\
\hline Radiology visits & $\begin{array}{l}.006 \\
(.005)\end{array}$ & $\begin{array}{l}.001 \\
(.002)\end{array}$ & $\begin{array}{l}.987 * \\
(.538)\end{array}$ & & $4.02 \%$ \\
\hline $\begin{array}{l}\text { Number of } \\
\text { observations }\end{array}$ & 90,598 & 90,598 & Varies & 90,598 & \\
\hline
\end{tabular}


Table 7: NAMCS Summary Statistics

Means and standard deviations

\begin{tabular}{|c|c|c|c|}
\hline Variable & Aged 55-64 & Age $65-75$ & Age $75+$ \\
\hline Duration of visit & $\begin{array}{c}18.85 \\
(14.25)\end{array}$ & $\begin{array}{c}18.51 \\
(13.71)\end{array}$ & $\begin{array}{c}18.23 \\
(13.32)\end{array}$ \\
\hline No follow-up planned & $\begin{array}{l}.068 \\
(.252)\end{array}$ & $\begin{array}{l}.052 \\
(.222)\end{array}$ & $\begin{array}{l}.046 \\
(.210)\end{array}$ \\
\hline Return at specified time & $\begin{array}{l}.671 \\
(.470)\end{array}$ & $\begin{array}{l}.719 \\
(.450)\end{array}$ & $\begin{array}{l}.739 \\
(.439)\end{array}$ \\
\hline Return if needed & $\begin{array}{l}.189 \\
(.392)\end{array}$ & $\begin{array}{l}.159 \\
(.365)\end{array}$ & $\begin{array}{l}.150 \\
(.357)\end{array}$ \\
\hline $\begin{array}{l}\text { Telephone follow-up } \\
\text { planned }\end{array}$ & $\begin{array}{l}.032 \\
(.176)\end{array}$ & $\begin{array}{l}.032 \\
(.177)\end{array}$ & $\begin{array}{l}.032 \\
(.177)\end{array}$ \\
\hline Refer to other physician & $\begin{array}{l}.034 \\
(.181)\end{array}$ & $\begin{array}{l}.031 \\
(.173)\end{array}$ & $\begin{array}{l}.032 \\
(.175)\end{array}$ \\
\hline $\begin{array}{l}\text { Return to referring } \\
\text { physician }\end{array}$ & $\begin{array}{l}.021 \\
(.143)\end{array}$ & $\begin{array}{l}.022 \\
(.145)\end{array}$ & $\begin{array}{l}.019 \\
(.136)\end{array}$ \\
\hline Admit to hospital & $\begin{array}{l}.015 \\
(.121)\end{array}$ & $\begin{array}{l}.017 \\
(.128)\end{array}$ & $\begin{array}{l}.017 \\
(.129)\end{array}$ \\
\hline Restriction & $\begin{array}{c}0 \\
(0)\end{array}$ & $\begin{array}{l}.482 \\
(.500)\end{array}$ & $\begin{array}{l}.501 \\
(.500)\end{array}$ \\
\hline Male & $\begin{array}{l}.442 \\
(.497)\end{array}$ & $\begin{array}{l}.450 \\
(.498)\end{array}$ & $\begin{array}{l}.410 \\
(.492)\end{array}$ \\
\hline Age & $\begin{array}{l}59.53 \\
(2.88)\end{array}$ & $\begin{array}{l}69.40 \\
(2.83)\end{array}$ & $\begin{array}{l}80.45 \\
(4.54)\end{array}$ \\
\hline Observations & 23,201 & 29,618 & 23,018 \\
\hline
\end{tabular}


Table 8: Quality of Medical Care

\begin{tabular}{|c|c|c|}
\hline Dependent variable & $\begin{array}{l}\text { Full sample } \\
\text { (Ages 55+) }\end{array}$ & Ages 55-75 \\
\hline $\begin{array}{l}\text { Duration of visit (in } \\
\text { minutes) }\end{array}$ & $\begin{array}{c}.012 \\
(.270)\end{array}$ & $\begin{array}{l}-.063 \\
(.244)\end{array}$ \\
\hline No follow-up planned & $\begin{array}{l}.005 \\
(.005)\end{array}$ & $\begin{array}{l}.005 \\
(.006)\end{array}$ \\
\hline Return at specified time & $\begin{array}{l}-.005 \\
(.008)\end{array}$ & $\begin{array}{l}-.007 \\
(.009)\end{array}$ \\
\hline Return if needed & $\begin{array}{l}-.001 \\
(.005)\end{array}$ & $\begin{array}{l}.002 \\
(.006)\end{array}$ \\
\hline $\begin{array}{l}\text { Telephone follow-up } \\
\text { planned }\end{array}$ & $\begin{array}{c}-.005 * * \\
(.002)\end{array}$ & $\begin{array}{c}-.006 * * \\
(.002)\end{array}$ \\
\hline Refer to other physician & $\begin{array}{l}.004 \\
(.003)\end{array}$ & $\begin{array}{l}.004 \\
(.003)\end{array}$ \\
\hline $\begin{array}{l}\text { Return to referring } \\
\text { physician }\end{array}$ & $\begin{array}{l}-.0004 \\
(.002)\end{array}$ & $\begin{array}{l}-.002 \\
(.002)\end{array}$ \\
\hline Admit to hospital & $\begin{array}{r}-.0003 \\
(.003) \\
\end{array}$ & $\begin{array}{c}-.00002 \\
(.003) \\
\end{array}$ \\
\hline Number of observations & 75,837 & 52,819 \\
\hline
\end{tabular}


Table 9: Quality of Medical Care

Shows coefficients on interaction with balance billing as a share of Medicare allowed charge

\begin{tabular}{|c|c|c|}
\hline Dependent variable & $\begin{array}{l}\text { Full sample } \\
(\text { Ages 55+) }\end{array}$ & Ages 55-75 \\
\hline $\begin{array}{l}\text { Duration of visit (in } \\
\text { minutes) }\end{array}$ & $\begin{array}{c}3.57 \\
(12.37)\end{array}$ & $\begin{array}{c}5.30 \\
(9.99)\end{array}$ \\
\hline No follow-up planned & $\begin{array}{l}.003 \\
(.218)\end{array}$ & $\begin{array}{l}.093 \\
(.235)\end{array}$ \\
\hline Return at specified time & $\begin{array}{l}.461 \\
(.418)\end{array}$ & $\begin{array}{l}.390 \\
(.460)\end{array}$ \\
\hline Return if needed & $\begin{array}{l}-.115 \\
(.266)\end{array}$ & $\begin{array}{l}-.316 \\
(.319)\end{array}$ \\
\hline $\begin{array}{l}\text { Telephone follow-up } \\
\text { planned }\end{array}$ & $\begin{array}{l}.053 \\
(.116)\end{array}$ & $\begin{array}{l}.067 \\
(.134)\end{array}$ \\
\hline Refer to other physician & $\begin{array}{l}.173 \\
(.157)\end{array}$ & $\begin{array}{l}.169 \\
(.147)\end{array}$ \\
\hline $\begin{array}{l}\text { Return to referring } \\
\text { physician }\end{array}$ & $\begin{array}{l}-.050 \\
(.097)\end{array}$ & $\begin{array}{l}-.038 \\
(.109)\end{array}$ \\
\hline Admit to hospital & $\begin{array}{l}-.092 \\
(.104) \\
\end{array}$ & $\begin{array}{l}-.093 \\
(.104) \\
\end{array}$ \\
\hline Number of observations & 71,752 & 49,761 \\
\hline
\end{tabular}


Table 10

Physician Per 1,000 Residents, by Specialty

\begin{tabular}{lcc}
\hline $\begin{array}{l}\text { Independent variable, interacted with } \\
\text { balance billing as a share of Medicare } \\
\text { allowed charge, } 1990\end{array}$ & $\begin{array}{c}(1) \\
\text { Doctors per } \\
1,000 \text { residents }\end{array}$ & $\begin{array}{c}(2) \\
\text { Doctors per } \\
1,000 \text { residents }\end{array}$ \\
\hline Restriction & $\begin{array}{c}-.00003 \\
(.00019)\end{array}$ & \\
Restriction, $\mathrm{t}=0$ & .000002 \\
& $(.0001)$ \\
Restriction, $\mathrm{t}=1$ & -.00003 \\
& & $(.00021)$ \\
Restriction, $\mathrm{t}>=2$ & $-.0005^{*}$ \\
& & $(.0003)$ \\
\hline Observations & 6,732 \\
\hline $\begin{array}{l}\text { Note. Standard errors in parentheses; they are clustered on state. Each column shows the coefficients from a different regression. } \\
\text { Controls include physician specialty, state, year and second-order interactions of these variables. Coefficients are estimated using }\end{array}$ \\
OLS. The mean of the dependent variable is 0.105 physicians per 1,000 residents.
\end{tabular}




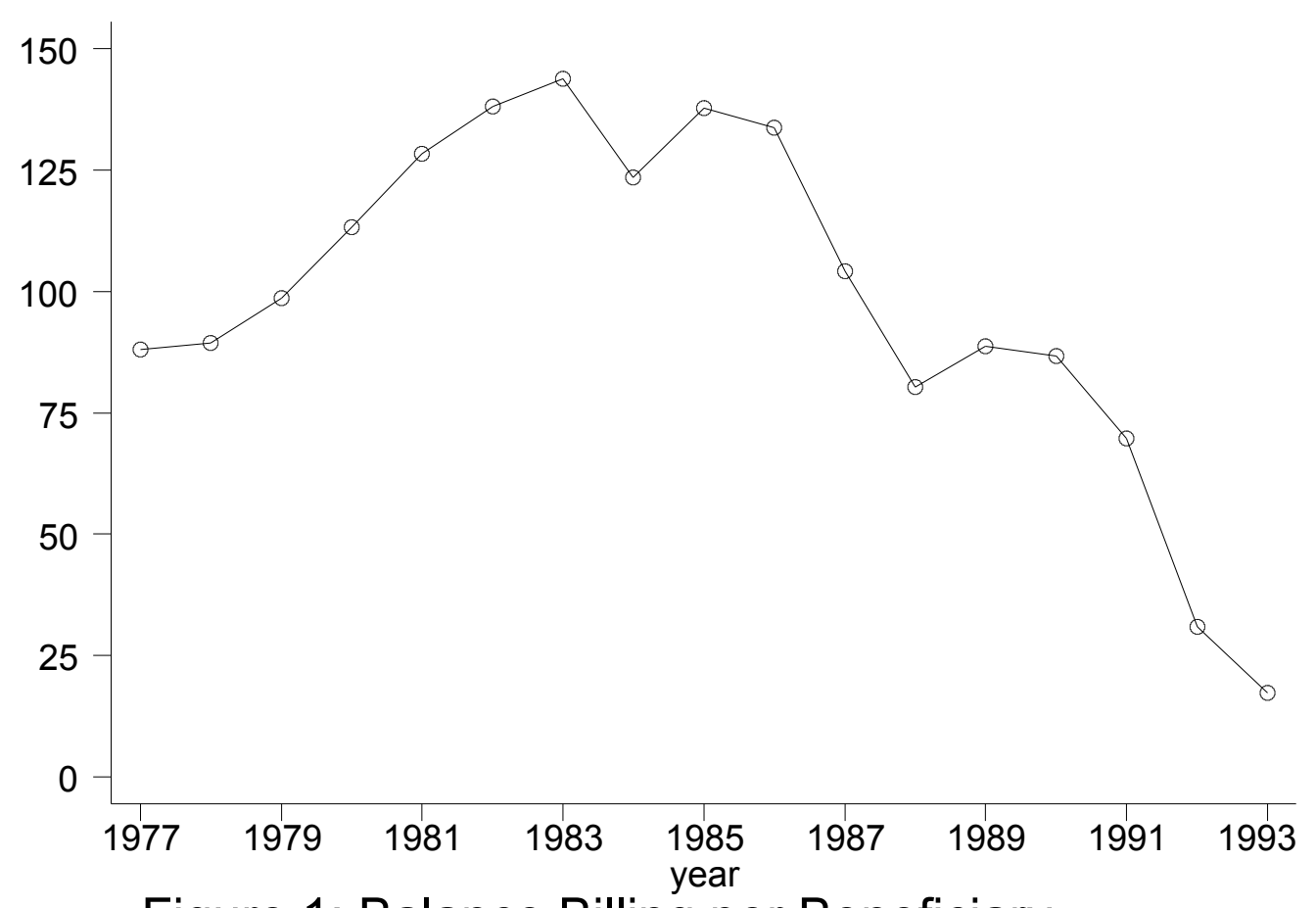

Figure 1: Balance Billing per Beneficiary

Source. Health Care Financing Administration (2000). 
Figure 2: The physician's maximization problem

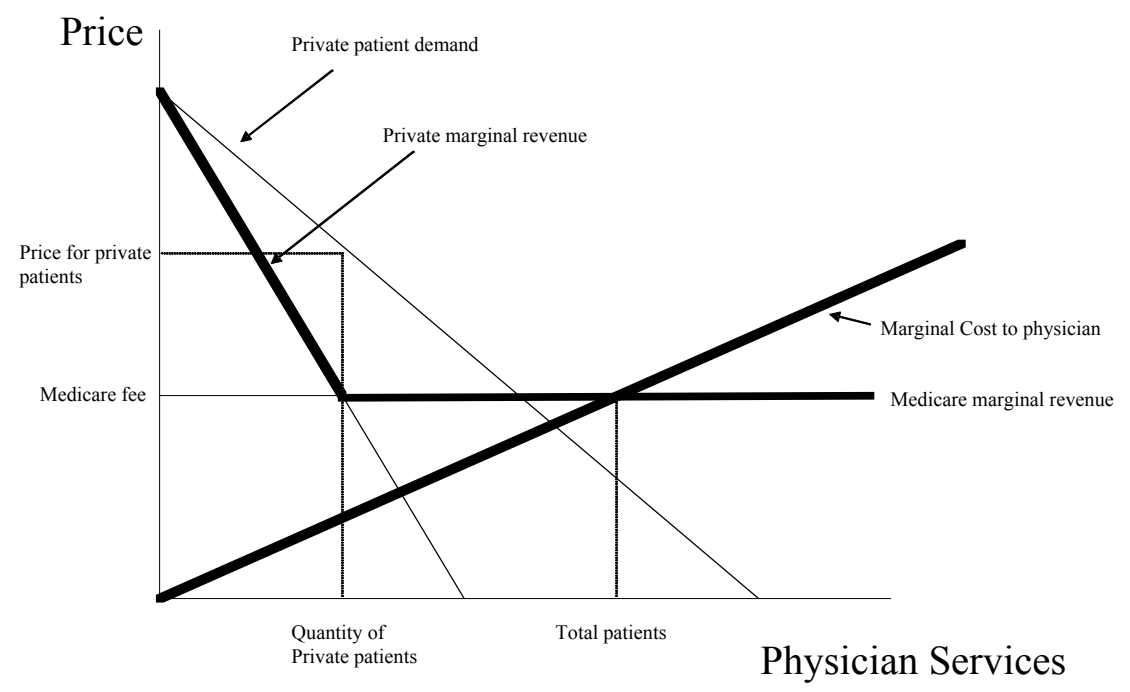

Figure 3: The physician's maximization problem when marginal costs are steep

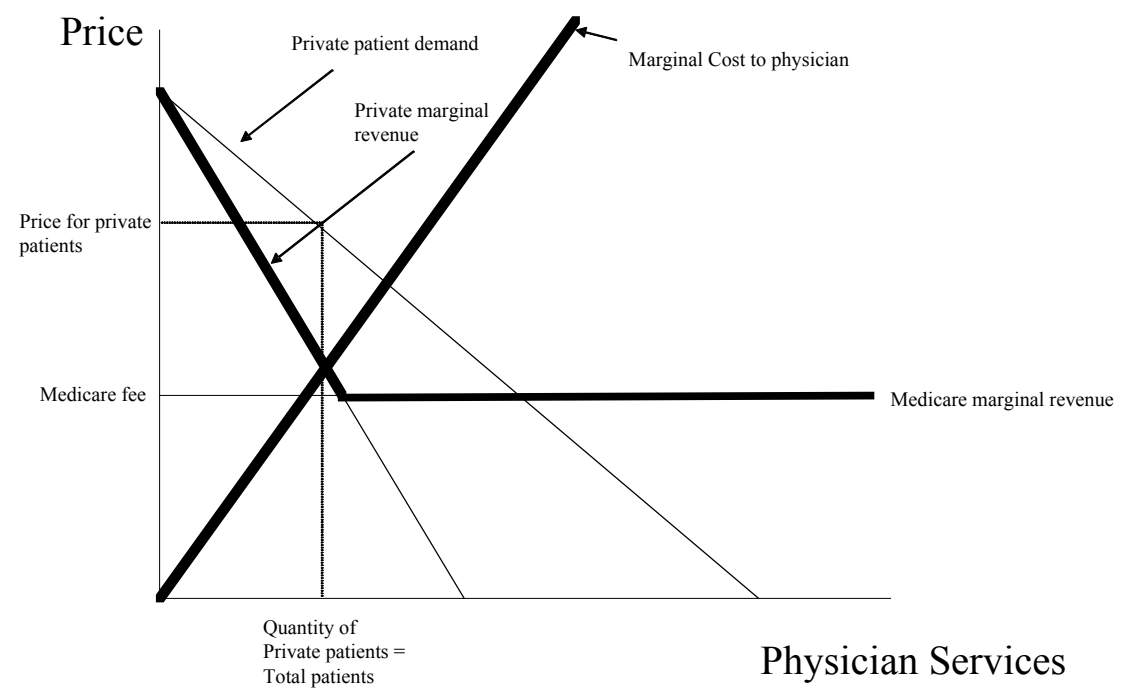




\section{Figure 4: The physician's maximization problem}

when balance billing is banned

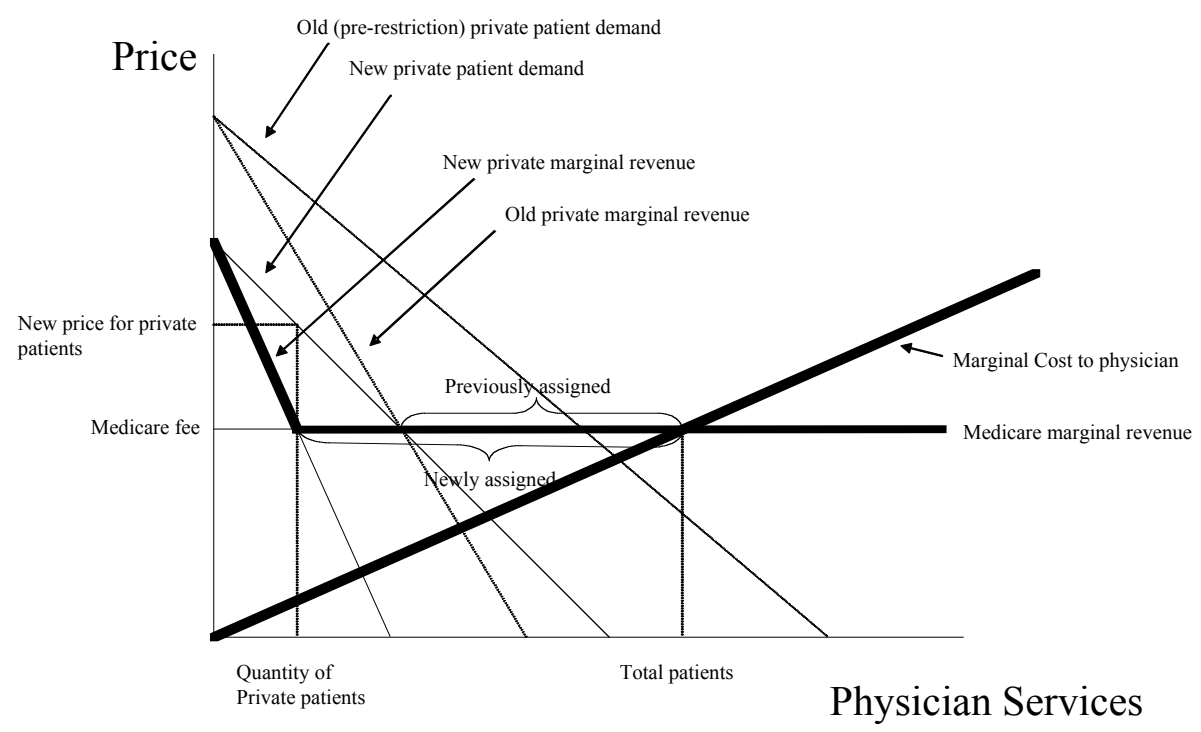

Figure 5: The Physician's Maximization Problem when balance billing is banned and Medicare fees decline

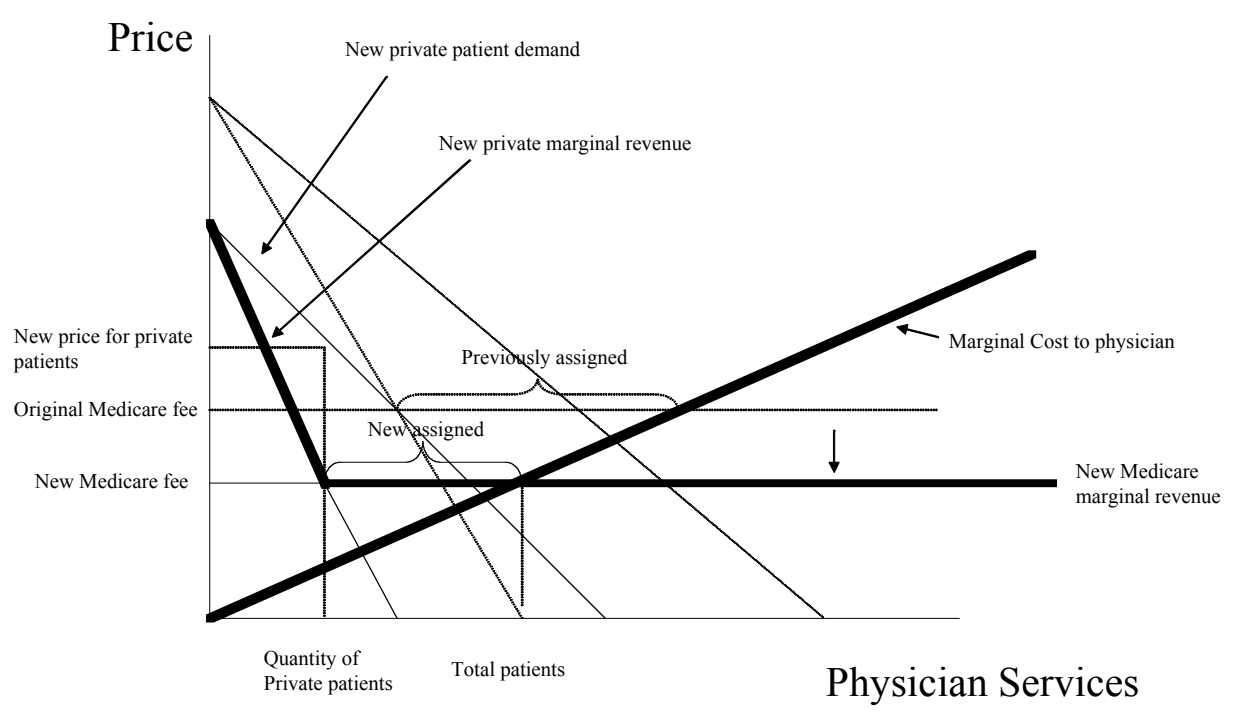

